\title{
A PESSOA IDOSA E SEU DIREITO PRIORITÁRIO À SAÚDE: APONTAMENTOS A PARTIR DO PRINCÍPIO DO MELHOR INTERESSE DO IDOSO
}

The elder and his right to health priority: notes from the principle of the best interest of the elderly

${ }^{1}$ Universidade Federal do Rio de Janeiro. Rio de Janeiro/RJ, Brasil.

Correspondência: Fabiana Rodrigues Barletta. E-mail: revdisan@usp.br.

Recebido em: 10/02/2014. Revisado em: 31/05/2014. Aprovado em: 02/06/2014. 


\section{RESUMO}

Este é artigo interdisciplinar que, por meio de revisão bibliográfica, estuda, sob a ótica do princípio do melhor interesse do idoso, o direito à saúde da pessoa idosa como autonomia e como condição para o exercício de outros direitos. Logo, atribui-se à saúde na velhice a qualidade de direito prioritário. O artigo conclui que há, na legislação brasileira, suficientes direitos a amparar o idoso, mas tais direitos carecem de concretude prática, o que demanda atuação das instituições democráticas, da iniciativa privada e dos cidadãos a fim de cumprir o projeto constitucional.

\section{Palavras-chave}

Direito Prioritário; Idoso; Melhor Interesse; Saúde.

\section{ABSTRACT}

This is an interdisciplinary paper which studies, through literature review, the right to health of the elderly such as autonomy and as a condition for the exercise of other rights, from the perspective of the principle of the best interests of the elderly. It is attributed to health in old age the quality of priority right. This article concludes that there are enough rights in Brazilian law to support the elderly, but these rights lack of practical concreteness, which demands action of the democratic institutions, private sector and citizens in order to fulfill the constitutional project.

\section{Keywords}

Elderly; Health; Principle of the Best Interest; Priority Rights. 


\section{Introdução}

O mundo dos grupos debilitados por limitações em sua saúde decorrentes da idade avançada não é igual ao mundo das pessoas de "idade normal”" e, a confirmar essa assertiva, análise estatística datada de 2004 informou que $40 \%$ da vida das pessoas idosas é vivida sem saúde ${ }^{2}$. Compreende-se que sobreviver num entorno de declínios de toda ordem, doenças e sofrimento definitivamente não é o mesmo que viver. Vida, do latim vita, diz-se um "conjunto de propriedades e qualidades graças às quais animais e plantas, ao contrário dos organismos mortos ou da matéria bruta, se mantêm em contínua atividade" ${ }^{3}$. Sim, para que exista vida, vidas humanas em específico, determinadas qualidades revelam-se imanentes, posto que o estado de estar vivo demanda atividade, pulsão, ação.

E o direito do idoso que se constrói no Brasil não quer que a velhice seja uma etapa de vida a ser vencida. Se concretizadas as leis que tutelam o idoso, teremos vidas saudáveis na velhice. Para tanto, faz-se necessário assegurar o caráter prioritário do Direito à saúde à pessoa idosa.

O Estatuto do Idoso, Lei 10.741/20034 , conhecida como Estatuto do Idoso, em seu artigo $8^{\circ}$ proclama que "o envelhecimento é um direito personalíssimo (...)". Nota-se, portanto, que envelhecer é direito da personalidade concedido de forma peculiar às pessoas de idades longevas ${ }^{5}$.

Se, de um lado, a velhice carrega consigo processos degenerativos intrínse$\cos ^{6}$, a medicina possui, por outro, instrumentos para que debilidades do envelhecimento não sejam experimentadas com violento sofrimento físico e psíquico. Há de se cumprir, portanto, o mandamento do artigo 15 do Estatuto do Idoso, que lhe assegura o direito à saúde de modo integral, incluindo, inclusive, atenção especial

\footnotetext{
${ }^{1}$ Segundo Norbert Elias, “Uma experiência de juventude assumiu certa significação para mim agora que estou mais velho. Assisti a uma conferência de um físico muito conhecido em Cambridge. Ele entrou devagar, arrastando os pés, um homem muito velho. 'Por que ele arrastava os pés assim? Por que não pode caminhar como um ser humano normal? ' Na hora, me corrigi: ‘Não pode evitar, é muito velho. Minha espontânea reação juvenil à visão de um velho é típica da espécie de sentimentos que a visão dos velhos suscita hoje, e talvez ainda mais em tempos passados, em pessoas saudáveis ou nos grupos de 'idade normal'”. ELIAS, Norbert. Envelhecer e morrer: alguns problemas sociológicos. In: ção de Plínio Dentizien. Rio de Janeiro: Jorge Zahar Editor, 2001. p. 79

${ }^{2}$ CAMARANO, Ana Amélia, KANSO, Solange; MELLO, Juliana Leitão e. Quão além dos 60 poderão viver os idosos brasileiros? In: CAMARANO, Ana Amélia (Org,). Os novos idosos brasileiros: muito além dos 60? Rio de Janeiro: IPEA, 2004. p. 103.

${ }^{3}$ FERREIRA, Aurélio Buarque de Holanda. Novo dicionário da língua portuguesa. 2 ed. Rio de Janeiro: Nova Fronteira, 1986.

${ }^{4}$ BRASIL. Lei $n^{\circ} 10.741$, de 01 de outubro de 2003. Dispõe sobre o Estatuto do Idoso e dá outras providências. Disponível em: <http://www.planalto.gov.br/ccivil_03/leis/2003/I10.741.htm>. Acesso em: 30 maio 2014.

${ }^{5}$ Segundo Adriano de Cupis, os direitos da personalidade são direitos subjetivos de essencialidade para a pessoa. DE CUPIS, Adriano. Os direitos da personalidade. Campinas: Romana, 2004. p. 29.

${ }^{6}$ RODRIGUES, Pais C.; RODRIGUES, Maria Manuel Pais. O doente idoso: patologia geral e terapêutica. Separata do Jornal do Médico, Porto, 1978. passim.
} 
às doenças que afetam preferencialmente os idosos, de forma expressamente prevista nessa regra. Desse modo, o direito à saúde é afiançado ao idoso de modo personalíssimo, garantidor de sua saúde na condição exclusiva de pessoa que vive o processo de senescência ${ }^{7}$.

É importante frisar que o direito dos nossos dias lida com categorias de pessoas vulneráveis, que necessitam de tratamento desigual no sentido material da desigualdade, ou seja, para sujeitos mais fracos haverá "direitos diferentes" idoso é mais fraco, dentre tantos outros fatores, também porque adoece mais. A vulnerabilidade do idoso por conta de seus declínios psicofísicos revela-se evidente.

Dar efetividade ao direito à saúde de pessoas em situações diferentes, porque idosas, implica afastá-las das doenças ou fazer com que seus efeitos sejam minimizados. Por conta da sensibilidade das pessoas idosas em relação às questões atinentes à sua saúde, que decorrem exatamente de suas suscetibilidades de ordem física e psíquica, que influem na social, seu direito a auferi-la deve ser diferenciado e maximizado, de forma que lhes seja concedida saúde de modo prioritário, posto que de maneira diferenciada.

\section{A saúde como autonomia e capacidade funcional: pressuposições para a qualidade de vida do idoso.}

A Constituição da Organização Mundial da Saúde (OMS) define saúde como "um estado de completo bem-estar físico, mental e social e não apenas a ausência de afecção ou doença".

Com esse significado, a saúde recebe o tratamento mais abrangente possível: uma pessoa que não apresente qualquer doença ainda não possui saúde se não tiver um completo bem-estar, quer dizer, um conteúdo concluído de bem-estar não só físico e mental, mas também social. Realmente, o teor abrangido pela definição de saúde da OMS serviria inclusive para conceituar felicidade.

Não se pretende, contudo, com essa primeira asserção criticar o critério adotado pela OMS para aferir saúde. Todo ser humano merece o estabelecido, e esse estado ideal de coisas deve ser constantemente buscado, pois restringi-lo poderia ocasionar um retrocesso social.

Paralelamente, a OMS define qualidade de vida como: "a percepção do indivíduo de sua posição na vida no contexto da cultura e sistemas de valores nos quais ele vive e em relação aos seus objetivos, expectativas, padrões e preocupações".

\footnotetext{
${ }^{7}$ Segundo Cláudia Lima Marques, “A proteção da vulnerabilidade do idoso faz nascer um direito subjetivo personalíssimo e indisponível ao envelhecimento sadio, ao qual corresponde uma multiplicidade de direitos e deveres para assegurá-lo". MARQUES, Cláudia Lima; MIRAGEM. Bruno. O novo direito privado e a proteção dos vulneráveis. São Paulo: Ed. Revista dos Tribunais, 2013. p. 145.

${ }^{8}$ Id. Ibid., p.16
} 
Aqui, o conteúdo apresentado toca à subjetividade de cada um, pois depende do que possa se aperceber, no sentido de sentir (presença), acerca de sua posição na vida (ocupação), no contexto da cultura e sistemas de valores nos quais se vive e também o seu sentimento em relação aos seus objetivos, expectativas, padrões e preocupações. De tal modo, mesmo que a vida de alguém pareça de altíssima qualidade aos olhos dos outros, ela não o será, se a específica pessoa assim não a conceber diante das experiências que compõem o seu eu (existência) ${ }^{9}$.

Mas ambas as definições são importantes para se construir uma acepção de saúde para a pessoa idosa, sem se esquecer de que o envelhecimento acarreta "trocas anatômicas e funcionais não produzidas por doenças" e que se diferem entre os indivíduos, mas que fazem parte de "um processo biológico intrínseco, declinante e universal, no qual se podem reconhecer marcas físicas e fisiológicas inerentes"10. Logo, questões de saúde envolvendo o idoso são diferentes de questões também atinentes à saúde de pessoas jovens por conta da vulnerabilidade psicofísica do idoso.

Na velhice, alterações anatômicas funcionais e doenças crônico-degenerativas apresentam-se irreversíveis, embora possam ser controladas pela medicina geriátrica. O grande problema enfrentado é o não controle dessas afecções, que gera sintomas desagradáveis, sequelas e complicações. "Estas serão responsáveis por deterioração rápida da capacidade funcional, surgindo incapacidade, dependência, perda de autonomia, necessidade de cuidados de longa duração e institucionalização" ${ }^{11}$.

Logo, proclamar saúde como um estado de completo bem-estar físico, mental e social, além da ausência de afecção ou doença para os anciãos em sua generalidade parece utópico, tendo em vista que não é comum envelhecer sem passar pelo mencionado processo biológico próprio do envelhecimento que, certamente, compromete a saúde percebida nos termos da $\mathrm{OMS}^{12}$.

Por outro lado, não se apregoa que velhice seja sinônimo de não saúde. A geriatria, no estágio em que se encontra, focaliza "a preservação e/ou a recuperação funcional" por meio de "uma abordagem diagnóstica multifacetada dos problemas físicos, psicológicos e funcionais" do idoso ${ }^{13}$. Aliás, considera-se possível gozar de

\footnotetext{
${ }^{9}$ As referências à presença, à ocupação e à existência remontam a Heidegger. HEIDEGGER, Martin. Ser e tempo. 7. ed. Petrópolis: Vozes, 2012. passim.

${ }^{10}$ FREITAS, Elizabete Viana de; MIRANDA, Roberto Dishinger; NERY, Mônica Rebouças. Parâmetros clínicos do envelhecimento e avaliação geriátrica global. In: FREITAS, Elizabete Viana de; PY, Ligia, NERI, Anita Liberanesso; CANÇADO, Flávio Aluízio Xavier; GORZONI, Milton Luiz; ROCHA, Sônia Maria da (Orgs.). Tratado de geriatria e gerontologia. Rio de Janeiro: Guanabara Koogan, 2002. p. 609.

${ }^{11}$ PASCHOAL, Sérgio Márcio Pacheco. Qualidade de vida na velhice. In: FREITAS, Elizabete Viana de; PY, Ligia, NERI, Anita Liberanesso; CANÇADO, Flávio Aluízio Xavier; GORZONI, Milton Luiz; ROCHA, Sônia Maria da (Orgs.). op. cit., p. 81.

${ }^{12}$ RAMOS, Luiz Roberto. Epidemiologia do envelhecimento. In: FREITAS, Elizabete Viana de; PY, Ligia, NERI, Anita Liberanesso; CANÇADO, Flávio Aluízio Xavier; GORZONI, Milton Luiz; ROCHA, Sônia Maria da (Orgs.). op. cit., p. 74-75.

${ }^{13}$ FREITAS, Elizabete Viana de; MIRANDA, Roberto Dishinger; NERY, Mônica Rebouças. op. cit., p. 617.
} 
uma velhice bem-sucedida preservando a saúde física e psíquica até a idade mais adiantada, observada como situação de bem-estar pessoal, familiar e social, tendo em vista que o envelhecer, na concepção dos cientistas e mesmo dos leigos, "não implica, necessariamente, doença e afastamento, e de que o idoso tem potencial para mudança e reservas de desenvolvimento inexploradas" 14 .

Compreende-se, portanto, que a autonomia da pessoa idosa deve ser buscada e preservada, haja vista que agir com autonomia decorre do exercício do direito constitucional à liberdade, de ordem fundamental e positivado em vários momentos na Constituição da República Brasileira de 1988. Se a pessoa idosa perde o poder de deliberar em suas atividades afetivas e negociais, torna-se tolhida no que diz respeito à sua autodeterminação, que também é um modo de manifestação da sua saúde, na forma do exercício dos seus direitos da personalidade ${ }^{15}$.

Fator que avalia determinantemente a qualidade de vida do idoso é a medida de sua autonomia ${ }^{16}$. A autonomia apresenta-se como a habilidade de definir e realizar seus próprios intentos; portanto, não envolve saber se o idoso é, independentemente de quão avantajada seja sua idade, hipertenso, diabético, cardíaco ou se é medicado com antidepressivos. Caso ele mantenha a aptidão para conduzir sua vida e decidir como e em que circunstâncias se dedicará ao trabalho em qualquer modalidade, ao lazer, ao cuidado consigo e aos relacionamentos e atividades sociais, apesar dos agravos apontados, seguramente será avaliado como uma pessoa saudável ${ }^{17}$.

O envelhecimento bem-sucedido, ou seja, saudável, consiste na soma da preservação da capacidade funcional à qualidade de vida experimentada, condições necessárias à autonomia da pessoa idosa. No entanto, faz-se imperioso ressaltar que a perda delas são conjecturas muito comuns na velhice, pois,

\footnotetext{
${ }^{14} \mathrm{FREIRE}$, Sueli Aparecida. A personalidade e o self na velhice: continuidade e mudança. In: FREITAS, Elizabete Viana de; PY, Ligia, NERI, Anita Liberanesso; CANÇADO, Flávio Aluízio Xavier; GORZONI, Milton Luiz; ROCHA, Sônia Maria da (Orgs.). op. cit., p. 929.

${ }_{15}^{15}$ CCuida-se da autonomia individual, da expressão da vontade como meio de desenvolvimento da personalidade do declarante. Esse indivíduo é a pessoa humana, independente do quanto tem, apenas como é. E como pessoa é indivíduo concreto, qualificado em cada relação jurídica que participa concretamente, de acordo com o valor da sua atividade e protegido segundo o seu grau de vulnerabilidade, a exemplo da criança e do adolescente, do idoso, do consumidor, etc." MEIRELES, Rose Melo Vencelau. Autonomia privada e dignidade humana. Rio de Janeiro: Renovar, 2009. p. 77.

16“Na velhice, a manutenção da autonomia e da independência estão intimamente ligadas à qualidade de vida. $\mathrm{A}$ autonomia e a independência, entre os idosos, são ótimos indicadores de saúde. Uma das formas de se qualificar a qualidade de vida de um idoso é avaliando-se o grau de autonomia que possui e o grau de independência com que desempenha as funções do dia-a-dia, sempre levando o contexto sociocultural em que vive. Isto porque é este que vai lhe oferecer oportunidades ou restrições para o exercício total ou parcial da independência e da autonomia. Contextos aceitadores e respeitadores dos direitos de todos os cidadãos, e que, por isso, ofereçam compensações e ajudas a cada um segundo a sua singularidade, têm maior capacidade para garantir a autonomia e a independência de seus membros, entre eles os idosos." LEMOS, Naira; MEDEIROS, Sônia Lima. Suporte social ao idoso dependente. In: FREITAS, Elizabete Viana de; PY, Ligia, NERI, Anita Liberanesso; CANÇADO, Flávio Aluízio Xavier; GORZONI, Milton Luiz; ROCHA, Sônia Maria da (Orgs.). op. cit., p. 893.

${ }^{17}$ RAMOS, Luiz Roberto. op. cit., p. 75.
} 
nessa altura da vida, corriqueiramente, ocorrem modificações funcionais que, não controladas, retiram dos anciãos a saúde. Na velhice, as situações mórbidas estão adjacentes, desencadeando-se com mais facilidade do que nas pessoas jovens, pois as capacidades de reserva e de defesa do idoso também se tornam menores. O envelhecimento proporciona a diminuição da disposição para se adaptar e o indivíduo fica muito mais vulnerável aos processos traumáticos, infecciosos e psicológicos.

Do mesmo modo, é habitual que a pressão arterial, o débito cardíaco, o equilíbrio hidroeletrolítico e o fluxo sanguíneo encontrem-se debilitados na velhice $^{18}$. No aparelho locomotor observa-se alteração na marcha, diferenciada dos mais jovens por desenvolver-se a passos curtos, mais lentos ou mesmo por pés que se arrastam; os movimentos dos braços perdem a amplidão, situando-se mais junto ao corpo. Na visão podem surgir as cataratas, degeneração macular, glaucoma e retinopatia diabética, além do decrescimento da habilidade visual por vários outros fatores decorrentes do envelhecimento. No aparelho auditivo há perda da acuidade, às vezes acompanhada por estados vertiginosos e zumbidos ${ }^{19}$. Acrescente-se que as demências e depressões são relativamente frequentes na maior idade ${ }^{20}$.

Enquanto na infância mais adiantada, na juventude e mesmo na idade adulta não próxima à velhice esses agravos são raros e, quando existentes, constituem desafios para a medicina e a ciência - uma vez que pés que se arrastam para conseguir se movimentar, ou demências degenerativas não são próprios da juventude -, na velhice esses transtornos são muitíssimo comuns.

Quando se é jovem apenas se usufrui da saúde sem sequer percebê-la, porque seu oposto, a doença, inexiste, usualmente. Enquanto gozar de saúde na juventude é algo natural, e as enfermidades consistem exceções à regra, permanecer saudável na velhice significa triunfar num entorno de adversidades que envolvem o ser envelhecido.

Por isso, ao tratar dos direitos fundamentais da pessoa idosa, o Estatuto do Idoso atrelou o direito à vida, à saúde e à dignidade na forma do artigo 9o: "É obrigação do Estado, garantir à pessoa idosa a proteção à vida e à saúde, mediante efetivação de políticas sociais públicas que permitam um envelhecimento saudável e em condições de dignidade".

Logo, envelhecer também é direito subjetivo exigível. E esse direito tem que ocorrer de forma saudável, em condições de dignidade.

\footnotetext{
${ }^{18}$ FREITAS, Elizabete Viana de; MIRANDA, Roberto Dishinger; NERY, Mônica Rebouças. op. cit., p. 611. ${ }^{19}$ Id., loc. cit.

${ }^{20}$ RAMOS, Luiz Roberto. op. cit., p. 75.
} 
Ressalta-se o conteúdo normativo do artigo em comento principalmente, pelo fato de ele agregar à vida saudável aquela que se dá em condições de dignidade. De nada adianta ao idoso estar vivo se não goza de bem-estar físico, psíquico e social, pois, sem esses predicados, não há que falar em vida nas condições de dignidade a que toda pessoa tem direito em qualquer época, e sim em um caminhar para a morte estereotipado pela involução ${ }^{21}$.

Trata-se, pois, de obrigação do Estado e da sociedade garantir à pessoa idosa a proteção à sua vida e à sua saúde por meio de políticas - públicas e privadas - que garantam um envelhecimento sadio ${ }^{22}$.

A partir do caráter normativo do princípio da dignidade da pessoa humana, todos fazem jus a viver dignamente, gozando de saúde, em qualquer etapa de sua existência. Como os idosos são propensos às enfermidades imanentes da velhice, sua saúde, quando em bom estado, deve ser preservada a todo custo e, quando deficitária, precisa ser reabilitada com primazia, pois saúde é vida em dignidade ${ }^{23}$.

\section{A saúde como condição para o exercício de outros direitos de ordem essencial}

Compreende-se que a existência digna dos anciãos também se compõe pelo acesso à educação, à cultura, ao esporte, ao lazer, à profissionalização e ao trabalho ${ }^{24}$. Mas sem saúde não há como desfrutar desses e de outros direitos tratados com especial atenção no Estatuto do Idoso. Resta evidente que, sem o ânimo que só um bom estado de saúde torna possível, não há espaço para a dose de esforço necessária à dedicação aos estudos, à profissionalização e ao trabalho.

${ }^{21}$ SCHMITT, Cristiano Heineck. Consumidores hipervulneráveis: a proteção do idoso no mercado de consumo. São Paulo: Atlas, 2014. p. 41.

${ }^{22}$ Gustavo Tepedino, quando fala das leis-incentivo, com finalidades específicas e do papel promocional do direito, tomando por base as lições de Norberto Bobbio. TEPEDINO, Gustavo. Premissas metodológicas para a constitucionalização do direito civil. In: . Temas de direito civil. 4. ed. Rio de Janeiro: Renovar, 2008. p. 8-12.

${ }^{23}$ Veja-se, por todos, Perlingeri: “A tutela da dignidade deve realizar-se em relação a todos os aspectos, sem, porém, que se deva traduzir na mesma situação de vantagem e na noção de direito subjetivo. (...) 0 mesmo interesse à saúde, indissolúvel daquele do livre desenvolvimento da pessoa, pode apresentar-se de formas diversas, assumindo relevância e configurações diversas, segundo seja visto como direito ao serviço sanitário, à salubridade do ambiente, à integridade física ou àquela mental: dependendo do fato que seja realizado mediante o esquema do interesse diretamente protegido ou daquele que o poder jurídico (potestá) e, portanto, do interesse legítimo. 0 que releva é o valor da pessoa unitariamente entendida. [grifos da autora] PERLINGIERI, Pietro. Perfis do direito civil: introdução ao direito civil constitucional. Tradução de Maria Cristina de Cicco. Rio de Janeiro: Renovar, 1997. p. 159.

${ }^{24}$ Anote-se, segundo informações trazidas ao conhecimento por Heloisa Helena Barboza, que a conceituação de saúde concebida pela $8^{\text {a }}$ Conferência Nacional de Saúde, realizada em 1986 é: “A saúde é a resultante das condições de Alimentação, Habitação, Educação, Renda, Meio Ambiente, Trabalho, Transporte, Lazer, Liberdade, Acesso a Posse de Terra e Acesso a Serviços de Saúde." BARBOZA, Heloisa Helena. A ética na saúde. In: BAYMA, Fátima; KASZNAR, Istvan (Orgs.). Saúde e previdência social: desafios para a gestão do próximo milênio. São Paulo: Makron Books, 2001. p. 177. 
Inclusive, se em condições deficitárias de saúde o entusiasmo do ancião é usurpado, retiram-se dele também, por conseguinte, as condições de se dedicar às atividades culturais, ao esporte, ao lazer e, mais uma vez, ao trabalho, que possui, para além da função de atividade que demanda esforço e dedicação, outras, não menos importantes. Em muitos casos, é o trabalho que proporciona sentimento de utilidade, possibilidade de vivência de experiências lúdicas e bem-estar psicológico ${ }^{25}$.

Portanto, conclui-se, pela frequência e rapidez em que na velhice a saúde se esvai, tornando o idoso mais suscetível aos agravos psicofísicos e ao alijamento social, que colocam em xeque uma vida saudável, sem a qual não há uma existência envolta pela dignidade, que assegurar o direito à saúde nessa etapa da vida constitui prioridade para a pessoa idosa.

Além disso, dentre os direitos fundamentais de segunda dimensão agasalhados pela Constituição da República, em seu artigo $6^{\circ}$, quais sejam, a educação, a saúde, a alimentação, o trabalho, a moradia, o lazer, a segurança, a previdência social, a proteção à maternidade e à infância e a assistência aos desamparados, ou seja, dentre aqueles direitos que, para se realizar, necessitam de condutas ativas do Estado ${ }^{26}$, a saúde exsurge como direito prioritário da pessoa idosa, pois, juntamente com a alimentação, a previdência e assistência, componentes da seguridade social no Brasil, ela é pré-requisito para que os idosos tenham acesso ao trabalho, à educação, à cultura, ao lazer, ao exercício dos direitos civis e políticos, em condições de liberdade e dignidade ${ }^{27}$.

Trata-se de um desafio não só para a medicina, mas também para o direito, que carrega os instrumentos para que o cuidado à pessoa seja efetivado, a garantia da saúde das pessoas que se encontram na velhice. Observe-se que esse cuidado tem um viés de condução, a guiar os caminhos do idoso e a estabelecer tratamento diferenciado segundo o princípio da proteção prioritária e o princípio da proteção integral que podem ser interpretados como concessão de autonomia ou como

\footnotetext{
${ }^{25}$ Segundo Alexandre Teixeira, "Entre os cidadãos desempregados do mundo todo, registram-se taxas maiores de infelicidade e suicídio do que na média das populações investigadas. Isso é verdade, inclusive, nos países europeus com os mais generosos estados de bem-estar social, onde o seguro-desemprego é suficiente para reduzir a níveis quase indolores o efeito da perda de renda que acompanha o desligamento do trabalho. 0 desemprego sempre aparece relacionado, por exemplo, com menor expectativa de vida e maiores riscos de ataque cardíaco. Exceto pelos casos de estresse severo causado pelo desespero de ordem econômica, o problema é psicológico e tem relação direta com a perda de sentido para as vidas de quem deixa de trabalhar. Mesmo quando não há uma queda dramática no padrão de vida." TEIXEIRA, Alexandre. Felicidade S.A.: por que a satisfação com o trabalho é a utopia possível no século XXI. Porto Alegre: Arquipélago Editorial, 2012. p. 47-48.

${ }^{26}$ CRUZ PARCERO, Juan Antonio. Los derechos sociales como técnica de protección jurídica. In: CARBONELL, Miguel; CRUZ PARCERO, Juan Antonio; VÁZQUEZ, Rodolfo (Comp.). Derechos sociales e derechos de las minorias. 2. ed. México: Editorial Porrúa, 2001. passim; QUEIROZ, Cristina M. M. Direitos fundamentais. Coimbra: Coimbra Ed., 2002. passim; PIETRO SANCHÍS, Luis. Los derechos sociales y el principio de igualdad sustancial. In: CARBONELL, Miguel; CRUZ PARCERO, Juan Antonio; VÁZQUEZ, Rodolfo (Comp.). op. cit., passim.

${ }^{27}$ Esse é um dos pontos centrais da tese que defendi em O direito à saúde da pessoa idosa. São Paulo: Saraiva, 2010. passim.
} 
concessão de assistência, sempre em busca do princípio do melhor interesse do idoso, que se concretiza na medida em que, no caso concreto, se efetiva o amparo ao idoso, que é dever do Estado, da família e da sociedade, propugnado pela Constituição da República, nos seus artigos 229 e $230^{28}$.

O princípio do melhor interesse do idoso nasce a partir de uma interpretação analógica de seu conteúdo dogmático-normativo com os conteúdos da mesma estirpe de proteção à criança e ao adolescente.

É imperioso relembrar que o princípio do melhor interesse da criança consta de uma convenção internacional ratificada pelo Brasil por meio do Decreto $99.710 / 1990^{29}$ e que constitui um princípio constitucional em vigor no ordenamento jurídico pátrio, em consonância com o disposto no artigo $5^{\circ}$, parágrafo $2^{\circ}$, da Constituição da República, que dispõe: "Os direitos e garantias expressos nesta Constituição não excluem outros decorrentes do regime dos princípios por ela adotados, ou dos tratados internacionais em que a República Federativa do Brasil seja parte". (grifos da autora)

Princípios são normas e é sabido que se "procederá à aplicação analógica das normas quando estas não contemplem uma hipótese específica, mas regulem outra semelhante entre elas que se aprecie identidade de razão"30.

Portanto, por analogia, como o ordenamento jurídico brasileiro acolhe, em diversos casos concretos, o princípio do melhor interesse da criança, também deve encampar o mesmo princípio a favorecer o idoso, pois a razão de o menor necessitar de um princípio especialíssimo, em razão de sua tenra idade, é o mesmo atribuído às pessoas de idade muito adiantada. Fragilidades em virtude da idade são comuns, embora em sentidos opostos, entre crianças, adolescentes e idosos. Por isso, a tutela especial dessas faixas etárias tem, guardadas as devidas proporções - na infância a saúde é delicada por conta do processo de

\footnotetext{
${ }^{28} \mathrm{Art}$. 229: "Os pais tem o dever de assistir, criar e educar os filhos menores, e os filhos maiores têm o dever de ajudar e amparar os pais na velhice, carência e enfermidade." (grifo da autora). Art. 230: "A família, a sociedade e o Estado têm o dever de amparar as pessoas idosas, assegurando sua participação na comunidade, defendendo sua dignidade e bem-estar e garantindo-lhes o direito à vida." (grifo da autora). BRASIL. Constituição da República Federativa do Brasil de 1988. Disponível em: <http://www.planalto.gov. br/ccivil_03/constituicao/constituicaocompilado.htm>. Acesso em: 31 maio 2014.

${ }^{29}$ BRASIL. Decreto n ${ }^{\circ}$ 99.710, de 21 de novembro de 1990. Promulga a Convenção sobre os Direitos da Criança. Disponivel em: <http://www.planalto.gov.br/ccivil_03/decreto/1990-1994/D99710.htm>. Acesso em: 31 maio 2014.

${ }^{30}$ Trata-se de ensinamento de Manuel Rodríguez. O autor também cita um exemplo de analogia: “As relações que se dão entre uma companhia de barcos de vapor e seus passageiros, que tenham tomado camarotes para sua comodidade durante a viagem, não difere em nenhum aspecto essencial da que se dá entre o hoteleiro e seus hóspedes. (...) As duas relações, se bem que não sejam idênticas, apresentam uma analogia tão estreita que deveria ser-lhes de aplicação a mesma regra de responsabilidade. Somos da opinião, por conseguinte, de que o demandado deveria verdadeiramente ser considerado como responsável pelo dinheiro roubado ao demandante, sem necessidade de prova alguma de negligência." [tradução livre do Espanhol]. ATIENZA RODRÍGUEZ. Manuel. Sobre la analogia em el derecho: ensayo de análisis de um razonamiento jurídico. Madrid: Civitas, 1986. p. 26.
} 
desenvolvimento do infante e na velhice a saúde tem essa qualidade pela senescência e a involução das capacidades -, a mesma razão de $\operatorname{ser}^{31}$.

Como o princípio do melhor interesse da criança e do adolescente e o princípio do melhor interesse do idoso são análogos por compartilharem a mesma característica, qual seja, a vulnerabilidade dessas pessoas em razão da idade, tal relação pode expressar-se também assim: o princípio do melhor interesse da criança e do adolescente existe e é válido porque crianças e adolescentes são vulneráveis, como o princípio do melhor interesse do idoso existe e é válido, porque os idosos são vulneráveis ${ }^{32}$.

Mais: o princípio do melhor interesse do idoso não se reduz a um princípio setorial; aliás, “as denominadas 'orientações setoriais' nem sempre são eficientes para a tutela da personalidade e dos direitos fundamentais da pessoa humana" ${ }^{33}$. Logo, o princípio de que se trata é expressão do princípio constitucional da dignidade da pessoa considerada em suas peculiaridades. Em outras palavras, "o princípio do melhor interesse do idoso, de base constitucional, é consectário natural da cláusula geral de tutela da pessoa e, por excelência, fonte da proteção integral que é devida ao idoso"34.

Frise-se: o princípio do melhor interesse do idoso também é recepcionado pelo artigo $5^{\circ}$, parágrafo $2^{\circ}$, da Constituição, no sentido de que os direitos e garantias expressos nela não excluem outros decorrentes do regime e dos princípios por ela adotados, recebendo, pois, a natureza de fundamental.

Faz-se, portanto, imperioso interpretar o direito a partir de um olhar acerca das diferenças, possibilitando a convivência de distintas gerações com o reconhecimento de sua identidade, bem como do que as aproxima e afasta, preservando, antes de tudo, a pessoa em sua situação singular ${ }^{35}$.

Destarte, "não existe um número fechado de hipóteses tuteladas: tutelado é o valor da pessoa sem limites, salvo aqueles colocados no seu interesse e naqueles de outras pessoas" ${ }^{36}$, como a colisão de interesses de pessoas idosas com outros interesses de crianças e adolescentes, situação na qual haverá necessidade de uma minuciosa ponderação.

\footnotetext{
31“ Quando os juristas falam de analogia, querem referir-se por comum a um procedimento argumentativo que permite transladar a solução prevista para um caso, a outro distinto, não regulado pelo ordenamento jurídico, mas que se assemelha ao primeiro enquanto que compartilha com aquele certas características essenciais ou bem - para empregar a solução clássica recolhida pelo Código Civil espanhol - a mesma razão (eadem ratio). [tradução livre do Espanhol]. ATIENZA RODRÍGUEZ. Manuel. op. cit., p. 29.

32"A relação de analogia pode formular-se sempre como uma analogia de relações: se dois conceitos ou os objetos denotados pelos mesmos, por exemplo, dois casos jurídicos, A e B, são análogos porque compartilham a característica $x$, dita relação pode expressar-se também assim: A está para $x$ como $B$ está para $x$. [tradução livre do Espanhol]. Id. Ibid., p. 35.

${ }^{33}$ BARBOZA, Heloisa Helena. O princípio do melhor interesse do idoso. In: PEREIRA, Tânia da Silva; OLIVEIRA, Guilherme de (Orgs.). O cuidado como valor jurídico. Rio de Janeiro: Forense, 2008. p. 70.

${ }^{34}$ Id. Ibid., p. 57.

${ }^{35}$ Veja-se, a propósito, GUTMANN, Amy. Identity in democracy. Princeton; Oxford: Princeton University Press, 2003. passim.

${ }^{36}$ PERLINGIERI, Pietro. op. cit., p. 156.
} 
O princípio do melhor interesse do idoso apresenta-se como princípio porque constitui critério teleológico-objetivo da interpretação a justificar a tomada de decisões em benefício do idoso; possui dimensão de peso, a qual ganhará relevância no sopesamento com outros princípios que com ele colidam; apresenta-se na modalidade de comando de otimização, ou seja, ordena que o melhor interesse se realize na maior medida possível, de acordo com as possibilidades jurídicas e fáticas; essas, dadas por um caso concreto ou abstrato envolvendo o idoso. O princípio analisado também possui como qualidade a determinação da realização de um fim juridicamente relevante, o melhor interesse do idoso, que só será realizado se adotado certo comportamento. Sua interpretação e aplicação demandam avaliação da correlação entre o estado de coisas colocado como fim - o melhor interesse do idoso - e os efeitos decorrentes dessa conduta tida como necessária, isto é, a efetividade do princípio na prática ${ }^{37}$.

O princípio do melhor interesse do idoso é consectário do princípio da dignidade da pessoa, que não tolera um tratamento formalmente igualitário e materialmente desigual entre pessoas de idades díspares em virtude das vulnerabilidades acarretadas pela velhice. Logo, a pessoa idosa é tutelada tanto pelo direito constitucional quanto pelas leis setoriais, em seus princípios e regras, levando-se em conta suas particularidades, seu momento de vida, em uma palavra: sua unicidade, para que não seja lesada em seus direitos, principalmente quando se trata da parte fraca de uma relação ou situação jurídica levada às Instituições Democráticas possuidoras dos poderes, para apreciação e decisão ${ }^{38}$.

Interpretar o direito dos idosos de acordo com o princípio do seu melhor interesse significa, em questões relativas à sua saúde, não só lhe conceder esse direito fundamental de maneira prioritária em relação aos seus outros direitos, mas também de lhe conferir prioridade no acesso à saúde em face de direitos concorrentes da mesma estirpe de pessoas de outras faixas etárias, e nesse caso o Poder Executivo tem o poder de implementar políticas desse jaez.

Também para se efetivar o princípio do melhor interesse do idoso, torna-se necessária estreita relação de balanceio entre doses de autonomia (no sentido de deixar a pessoa idosa livre, apesar de possuir alguns declínios) e doses de proteção (no sentido de assistir a pessoa idosa com atenção diferenciada), pois, para

\footnotetext{
${ }^{37}$ Partiu-se da construção sobre princípios e regras de Humberto Ávila, com quem se concorda, nesse ponto. ÁVILA, Humberto. Teoria dos princípios: da definição à aplicação dos princípios jurídicos. 2. ed. São Paulo: Malheiros Ed., 2003. p. 65.

${ }^{38}$ Observe-se o magistério de Francisco Amaral: "A interpretação jurídica não tem por objetivo descobrir o sentido e o alcance de uma regra jurídica, mas sim, constituir-se na primeira fase de um processo de construção ou concretização da norma jurídica adequada ao caso concreto. Apresentando-se as regras jurídicas como proposições linguísticas de caráter geral, deve o intérprete, a partir do seu texto, construir a norma-decisão específica para o caso em tela, tendo em vista o ser humano in concreto, situado, não o sujeito de direito in abstracto, próprio do direito liberal da modernidade." AMARAL, Francisco. O Código Civil brasileiro e o problema metodológico de sua realização: do paradigma da aplicação ao paradigma judicativo decisório. Revista Forense, Rio de Janeiro, v. 102, n. 385, p. 97, maio/jun. 2006.
} 
preservar a autonomia do idoso, é necessário antes cuidado com sua saúde. Forçoso, portanto, é tratar a saúde como direito prioritário nas idades adiantadas para que as pessoas idosas, efetivamente, desfrutem não só dos direitos comuns a todos os seres humanos, mas também dos que a maior idade lhes garante.

Assim como ter saúde é pré-requisito para o acesso à educação, à cultura, ao esporte e ao lazer, às diversões e aos espetáculos, a vivência dessas atividades proporciona melhor qualidade de vida e, portanto, de saúde, para a pessoa idosa, principalmente por serem oferecidas juntamente com o respeito por sua peculiar condição de idade, na forma do artigo 20 do Estatuto do Idoso.

Desse modo, a lei estabelece que a educação na velhice seja incentivada pelo poder público, que também fará por adequar currículos, metodologias e material didático aos programas educacionais com essa destinação, como dispõe o caput do artigo 21 do Estatuto. Na forma do parágrafo primeiro do citado artigo, "os cursos especiais para idosos incluirão conteúdo relativo às técnicas de comunicação, computação e demais avanços tecnológicos, para sua integração à vida moderna", e, de acordo com o subsequente parágrafo segundo, "os idosos participarão das comemorações de caráter cívico ou cultural, para transmissão de conhecimentos e vivências às demais gerações, no sentido da preservação da memória e da identidade culturais".

Muitíssimo importante para a inserção social do idoso, posto que se relaciona intimamente com a preservação de sua saúde, é a fixação nos diversos níveis de ensino formal de conteúdos voltados ao processo de envelhecimento, ao respeito e à valorização dessas pessoas a fim de eliminar o preconceito e produzir conhecimentos sobre a matéria, como disciplina o artigo 22 do Estatuto. No mesmo sentido, o apoio do Poder Público à criação de universidades abertas para as pessoas idosas, bem como à publicação de livros e periódicos de conteúdo e padrões editoriais adequados a essa faixa etária, considerando, até mesmo, a natural redução de sua capacidade visual, afiguram-se como contributos à inclusão do idoso, previstos no art. 25 do seu Estatuto ${ }^{39}$. Note-se que a promoção da educação dos anciãos no Brasil pode dizer respeito tanto à educação básica, a que muitos não tiveram acesso, quanto à que abranja a continuidade dos seus estudos ${ }^{40}$.

Proporcionar informações, educação, ingresso nos ambientes das artes e da cultura em horários ou espaços especialmente voltados aos idosos também enriquece qualitativamente suas vidas, de modo a lhes proporcionar desenvolvimento pessoal e participação social ${ }^{41}$, o que inegavelmente contribui para sua saúde psíquica. Tais projetos serão levados até eles pelos meios de comunicação, consoante o artigo 24 do Estatuto do Idoso.

\footnotetext{
${ }^{39}$ Seja consentido remeter a Fabiana Rodrigues Barletta. Trata-se de um áudio-livro dirigido não só, mas especialmente, aos idosos, considerando suas possíveis dificuldades com a leitura, informando-os seus direitos. BARLETTA, Fabiana Rodrigues. Tudo que você precisa ouvir sobre direitos dos idosos. São Paulo: Saraiva 2011. ${ }^{40}$ RULLI NETO, Antonio. Proteção legal do idoso no Brasil. São Paulo: Fiuza Editores, 2003. p. 185.

${ }^{41}$ Id. Ibid., p. 192.
} 
Há de se considerar também a importância para o bem-estar e a saúde psicofísica do idoso o fato de ele ter acesso ao trabalho remunerado ${ }^{42}$ ou não, pois este último tem o condão de implementar ainda sua socialização, inclusive, pela possibilidade de contato direto, no trabalho em grupo, ou indireto, no caso dos intelectuais e autônomos, com outras pessoas de sua e de distintas gerações. O contato social intergeracional é, de todo, inclusivo para o idoso. Veja-se que o artigo 26 do Estatuto do Idoso prevê que "o idoso tem direito ao exercício de atividade profissional, respeitadas suas condições físicas, intelectuais e psíquicas".

O direito ao trabalho tem o papel de promover o exercício de funções pela pessoa idosa objetivando retirá-la da qualidade de inativa, o que eliminaria sua produtividade, considerando, contudo, que não deve lhe impor cobranças exageradas, o que poderia surtir um efeito indesejado em sua saúde ${ }^{43}$. Há de se ter em conta o valor do trabalho para a continuidade da autonomia dos anciãos, estreitamente relacionado com sua qualidade de vida, pois, quando adequado ao idoso, com observância de suas minudências, o trabalho ocupa, distrai e pode, por consequência, propiciar prazer físico e psíquico ${ }^{44}$.

Ao ser admitido em qualquer emprego ou trabalho, mesmo no ingresso por concurso, ressalvados casos em que a ocupação exija habilidades que o idoso não possua ${ }^{45}$, vedam-se sua discriminação e a limitação de idade, e o primeiro critério de desempate em concurso público privilegia as pessoas de idade mais avançada, conforme o artigo 27 e parágrafo único do Estatuto do Idoso. Inclusive, obstar ou negar a alguém, por motivo de idade, acesso a qualquer cargo público, emprego ou trabalho constitui crime tipificado pelo artigo 100, incisos I e II, da referida lei. O Estatuto oferece ainda estímulos aos programas voltados para o trabalho do idoso e para uma aposentadoria ativa, como disciplina seu artigo $28^{46}$.

\footnotetext{
${ }^{42}$ É frequente a necessidade dos idosos de continuarem trabalhando para auferirem algum acréscimo a sua renda, porque a previdência social, na grande maioria dos casos, não preserva a situação econômica do aposentado.

${ }^{43}$ De acordo com Melissa Pérola Braga, “Deve-se buscar um meio termo entre o velho estereotipado, que se limitava a ficar ociosamente em casa, dando trabalho para seus familiares, e aquele idoso de quem se exija que entre em competição com os mais novos, em permanente disputa por uma maior produção e participação na sociedade." BRAGA, Pérola Melissa V. Direitos do idoso segundo o estatuto do idoso. São Paulo: Quartier Latin, 2005. p. 58.

${ }^{44}$ BRAGA, Pérola Melissa V. op. cit., p 143.

${ }^{45}$ Roberto Mendes de Freitas Junior traz à baila importante observação: “Vale notar respeitável corrente jurisprudencial, sustentando que a imposição de limite máximo deverá decorrer de lei infraconstitucional, sendo vedado ao administrador a imposição aleatória, em determinado concurso público, sem o devido respaldo legal." FREITAS JR. Roberto Mendes de. Direitos do idoso. In: FREITAS, Elizabete Viana de; PY, Ligia, NERI, Anita Liberanesso; CANÇADO, Flávio Aluízio Xavier; GORZONI, Milton Luiz; ROCHA, Sônia Maria da (Orgs.). op. cit., p. 127.

${ }^{46}$ Art. 28: "O Poder Público criará e estimulará programas de: I - profissionalização especializada para os idosos, aproveitando seus potenciais e habilidades para atividades regulares e remuneradas; II - preparação dos trabalhadores para a aposentadoria, com antecedência máxima de 1 (um) ano, por meio de estímulo a novos projetos sociais, conforme seus interesses, e de esclarecimento sobre os direitos sociais e de cidadania; III - estímulo às empresas privadas para admissão de idosos ao trabalho." BRASIL. Lei n 10.741, de 01 de outubro de 2003, cit.
} 
Os mandamentos legais do artigo 28 necessitam de políticas públicas para que sejam implementados. Considera-se, pois, pertinente, o estímulo às empresas privadas na contratação de idosos, mediante isenções ou reduções fiscais e propaganda dessas empresas ${ }^{47}$. O direito ao transporte gratuito também possibilita o acesso do idoso aos hospitais, laboratórios, clínicas, ou seja, a lugares em que sua saúde vá ser assistida. Mas não apenas. O transporte também conduz o idoso ao trabalho e ao lazer, ao acesso à cultura e à educação ${ }^{48}$.

Tais direitos, previstos no Estatuto do Idoso como fundamentais, propiciam melhores condições de existência para a pessoa idosa.

Sublinhe-se, entretanto, que em condições extremas esses direitos podem até faltar, mas a saúde (no sentido oposto ao da doença), não. A saúde é assaz necessária e inafastável, não só como condição de gozo desses direitos. Usufruir deles também propicia saúde por influir na qualidade de vida dos idosos.

\section{Considerações finais}

O Brasil possui uma Constituição dirigente que vinculou o legislador quando, em 2003, o Estatuto do Idoso foi decretado e sancionado ${ }^{49}$.

Uma Constituição com esse signo não vincula somente o legislador, mas também as demais instituições democráticas - com seus poderes argumentativos, decisórios e executórios -, a fazerem valer os objetivos fundamentais da República brasileira que, quando toca nos direitos dos idosos, opta por promover seu bem por meio do amparo, não permitindo a discriminação pela idade, ou, dito de outra forma, discrimina-os positivamente, garantindo-lhes ferramentas para que não se afastem radicalmente das condições biopsíquicas das pessoas de outras gerações ${ }^{50}$.

Mas não é só. A Constituição vincula também a autonomia privada e cada cidadão ao seu projeto, de modo que a sociedade, composta pela iniciativa privada e por seus cidadãos, possui a responsabilidade de implementar políticas em favor do idoso e também cobrar políticas públicas e decisões judiciais voltadas para a concessão de saúde à pessoa idosa na medida da sua

\footnotetext{
${ }^{47}$ FREITAS JR. Roberto Mendes de. op. cit., p.128.

${ }^{48}$ No que diz respeito aos direitos do idoso especificamente como consumidor, ver GRAEFF, Bibiana. Direitos do consumidor idoso no Brasil. Revista de Direito do Consumidor, São Paulo, v. 22, n. 86, p. 69-70, mar./ abr. 2013, onde identifica um regime jurídico aplicável especificamente ao consumidor idoso na esfera do transporte e do estacionamento, face às instituições de atendimento, do usufruto da meia-entrada nos eventos e de não terem suas prestações aumentadas em razão da idade nos contratos de plano de saúde. Ver também SCHMITT, Cristiano Heineck. op. cit., passim.

${ }^{49}$ Expressão cunhada por José Canotilho. CANOTILHO, José Joaquim Gomes. Constituição dirigente e vinculação do legislador. 2. ed. Coimbra: Coimbra Ed., 2001. passim.

${ }^{50}$ Art. $3^{\circ}$, IV: "Constituem objetivos fundamentais da República Federativa do Brasil: (...) promover o bem de todos, sem preconceitos de origem, raça, sexo, cor, idade e quaisquer outras formas de discriminação." BRASIL. Constituição da República Federativa do Brasil de 1988, cit.
} 
necessidade. Movimentos democráticos institucionalizados devem desempenhar esse papel se os Poderes Executivo e Judiciário não caminharem no sentido de operar o direito à saúde da pessoa idosa que a lei - constitucional e infraconstitucional - garante amplamente.

Não parecem poucos os direitos conferidos aos idosos, mas escasso é o seu exercício, posto que, na prática, muitas vezes, não se concretizam.

Por conta de o idoso estar mais exposto às agressões tanto biológicas, provocadas pelo tempo, quanto às de índole social que necessita enfrentar; pelo fato de as alterações biológicas sofridas desencadearem doenças físicas, psíquicas e neurológicas com mais facilidade e em maior pujança que na juventude, é imperioso que o direito à saúde na terceira idade seja concedido em ordem de prioridade, para salvaguarda do princípio constitucional da dignidade humana do qual emana o princípio do melhor interesse do idoso nas contingências especialíssimas da velhice.

\section{Referências}

AMARAL, Francisco. O Código Civil brasileiro e o problema metodológico de sua realização: do paradigma da aplicação ao paradigma judicativo decisório. Revista Forense, Rio de Janeiro, v. 102, n. 385, p. 87-100, maio/jun. 2006.

ATIENZA RODRÍGUEZ. Manuel. Sobre la analogia em el derecho: ensayo de análisis de um razonamiento jurídico. Madrid: Civitas, 1986.

ÁVILA, Humberto. Teoria dos princípios: da definição à aplicação dos princípios jurídicos. 2. ed. São Paulo: Malheiros Ed., 2003.

BARBOZA, Heloisa Helena. A ética na saúde. In: BAYMA, Fátima; KASZNAR, Istvan (Orgs.). Saúde e previdência social: desafios para a gestão do próximo milênio. São Paulo: Makron Books, 2001.

BARBOZA, Heloisa Helena. O princípio do melhor interesse do idoso. In: PEREIRA, Tânia da Silva; OLIVEIRA, Guilherme de (Orgs.). O cuidado como valor jurídico. Rio de Janeiro: Forense, 2008.

BARLETTA, Fabiana Rodrigues. O direito à saúde da pessoa idosa. São Paulo: Saraiva, 2010.

Fabiana Rodrigues. Tudo que você precisa ouvir sobre direitos dos idosos. São Paulo: Saraiva 2011.

BRAGA, Pérola Melissa V. Direitos do idoso segundo o estatuto do idoso. São Paulo: Quartier Latin, 2005.

CAMARANO, Ana Amélia, KANSO, Solange; MELLO, Juliana Leitão e. Quão além dos 60 poderão viver os idosos brasileiros? In: CAMARANO, Ana Amélia (Org,). Os novos idosos brasileiros: muito além dos 60? Rio de Janeiro: IPEA, 2004. 
CANOTILHO, José Joaquim Gomes. Constituição dirigente e vinculação do legislador. 2. ed. Coimbra: Coimbra Ed., 2001.

CONTRERAS PELÁEZ, Francisco J. Derechos sociales: teoría e ideologia. Madrid: Tecnos, 1994.

CRUZ PARCERO, Juan Antonio. Los derechos sociales como técnica de protección jurídica. In: CARBONELL, Miguel; CRUZ PARCERO, Juan Antonio; VÁZQUEZ, Rodolfo (Comp.). Derechos sociales e derechos de las minorias. 2. ed. México: Editorial Porrúa, 2001.

DE CUPIS, Adriano. Os direitos da personalidade. Campinas: Romana, 2004.

ELIAS, Norbert. Envelhecer e morrer: alguns problemas sociológicos. In: A solidão dos moribundos. Rio de Janeiro: Jorge Zahar Editor, 2001.

FERREIRA, Aurélio Buarque de Holanda. Novo dicionário da língua portuguesa. 2 ed. Rio de Janeiro: Nova Fronteira, 1986.

FREIRE, Sueli Aparecida. A personalidade e o self na velhice: continuidade e mudança. In: FREITAS, Elizabete Viana de; PY, Ligia, NERI, Anita Liberanesso; CANÇADO, Flávio Aluízio Xavier; GORZONI, Milton Luiz; ROCHA, Sônia Maria da (Orgs.). Tratado de geriatria e gerontologia. Rio de Janeiro: Guanabara Koogan, 2002.

FREITAS JR. Roberto Mendes de. Direitos do idoso. In: FREITAS, Elizabete Viana de; PY, Ligia, NERI, Anita Liberanesso; CANÇADO, Flávio Aluízio Xavier; GORZONI, Milton Luiz; ROCHA, Sônia Maria da (Orgs.). Tratado de geriatria e gerontologia. Rio de Janeiro: Guanabara Koogan, 2002.

FREITAS, Elizabete Viana de; MIRANDA, Roberto Dishinger; NERY, Mônica Rebouças. Parâmetros clínicos do envelhecimento e avaliação geriátrica global. In: FREITAS, Elizabete Viana de; PY, Ligia, NERI, Anita Liberanesso; CANÇADO, Flávio Aluízio Xavier; GORZONI, Milton Luiz; ROCHA, Sônia Maria da (Orgs.). Tratado de geriatria e gerontologia. Rio de Janeiro: Guanabara Koogan, 2002.

GRAEFF, Bibiana. Direitos do consumidor idoso no Brasil. Revista de Direito do Consumidor, São Paulo, v. 22, n. 86, mar./abr. 2013.

GUTMANN, Amy. Identity in democracy. Princeton; Oxford: Princeton University Press, 2003.

HEIDEGGER, Martin. Ser e tempo. 7. ed. Petrópolis: Vozes, 2012.

LEMOS, Naira; MEDEIROS, Sônia Lima. Suporte social ao idoso dependente. In: FREITAS, Elizabete Viana de; PY, Ligia, NERI, Anita Liberanesso; CANÇADO, Flávio Aluízio Xavier; GORZONI, Milton Luiz; ROCHA, Sônia Maria da (Orgs.). Tratado de geriatria e gerontologia. Rio de Janeiro: Guanabara Koogan, 2002.

MARQUES, Cláudia Lima; MIRAGEM. Bruno. O novo direito privado e a proteção dos vulneráveis. São Paulo: Ed. Revista dos Tribunais, 2013.

MEIRELES, Rose Melo Vencelau. Autonomia privada e dignidade humana. Rio de Janeiro: Renovar, 2009. 
PASCHOAL, Sérgio Márcio Pacheco. Qualidade de vida na velhice. In: FREITAS, Elizabete Viana de; PY, Ligia, NERI, Anita Liberanesso; CANÇADO, Flávio Aluízio Xavier; GORZONI, Milton Luiz; ROCHA, Sônia Maria da (Orgs.). Tratado de geriatria e gerontologia. Rio de Janeiro: Guanabara Koogan, 2002.

PERLINGIERI, Pietro. Perfis do direito civil: introdução ao direito civil constitucional. Rio de Janeiro: Renovar, 1997.

PIETRO SANCHÍS, Luis. Los derechos sociales y el principio de igualdad sustancial. In: CARBONELL, Miguel; CRUZ PARCERO, Juan Antonio; VÁZQUEZ, Rodolfo (Comp.). Derechos sociales e derechos de las minorias. 2. ed. México: Editorial Porrúa, 2001.

QUEIROZ, Cristina M. M. Direitos fundamentais. Coimbra: Coimbra Ed., 2002.

RAMOS, Luiz Roberto. Epidemiologia do envelhecimento. In: FREITAS, Elizabete Viana de; PY, Ligia, NERI, Anita Liberanesso; CANÇADO, Flávio Aluízio Xavier; GORZONI, Milton Luiz; ROCHA, Sônia Maria da (Orgs.). Tratado de geriatria e gerontologia. Rio de Janeiro: Guanabara Koogan, 2002.

RODRIGUES, Pais C.; RODRIGUES, Maria Manuel Pais. O doente idoso: patologia geral e terapêutica. Separata do Jornal do Médico, Porto, 1978.

RULLI NETO, Antonio. Proteção legal do idoso no Brasil. São Paulo: Fiuza Editores, 2003.

SCHMITT, Cristiano Heineck. Consumidores hipervulneráveis: a proteção do idoso no mercado de consumo. São Paulo: Atlas, 2014.

TEIXEIRA, Alexandre. Felicidade S.A.: por que a satisfação com o trabalho é a utopia possível no século XXI. Porto Alegre: Arquipélago Editorial, 2012.

TEPEDINO, Gustavo. Premissas metodológicas para a constitucionalização do direito civil. In: __ . Temas de direito civil. 4. ed. Rio de Janeiro: Renovar, 2008.

Fabiana Rodrigues Barletta - Mestre em Direito Civil pela Universidade do Estado do Rio de Janeiro; Doutora em Teoria do Estado e Direito Constitucional pela Pontifícia Universidade Católica do Rio de Janeiro. Professora Adjunta, Universidade Federal do Rio de Janeiro. Rio de Janeiro/RJ, Brasil.E-mail: revdisan@usp.br. 